\title{
Enteroviral infection causing fatal myocarditis and subclinical myopathy
}

\author{
E Arbustini, E Porcu, O Bellini, M Grasso, A Pilotto, B Dal Bello, P Morbini, M Diegoli, \\ A Gavazzi, G Specchia, L Tavazzi
}

Department of Pathology, IRCCS-Policlinico San Matteo, Pavia, Italy

E Arbustini

O Bellini

A Pilotto

B Dal Bello

P Morbini

M Diegoli

Transplantation

Experimental

Laboratory,

IRCCS-Policlinico San

Matteo

E Porcu

M Grasso

Department of

Cardiology,

IRCCS-Policlinico San

Matteo

A Gavazzi

G Specchia

L Tavazzi

Correspondence to: Dr E Arbustini, Istituto di Anatomia Patologica, Viale Forlanini 16, 27100 Pavia, Italy.

email: e.arbustini@

smatteo.pv.it

Accepted for publication 11 February 1999

\begin{abstract}
Enteroviral RNA detection in myocarditis and dilated cardiomyopathy is rare. Enteroviral particles and RNA have recently been identified in patient's skeletal muscle, suggesting that skeletal more than heart muscle hosts the virus in chronic infection. Enteroviral RNA and virus-like particles were found in the myocardium and in the skeletal muscle of two patients with fatal myocarditis: a 39 year old man who died five days after the onset of febrile flu; and a 49 year old woman, assisted for 50 days with a left ventricular assist device, who then died from cerebral haemorrhage. Automated sequencing, alignment, and sequence comparison confirmed the enteroviral origin of polymerase chain reaction products and excluded contamination. These findings agree with prior observations of enteroviral localisation in the skeletal muscle of patients with dilated cardiomyopathy, and further support the hypothesis that skeletal rather than heart muscle may host the virus and serve as a reservoir in cardiomyopathies related to chronic infection.

(Heart 2000;83:86-90)
\end{abstract}

Keywords: enterovirus; myocarditis; viral particles; skeletal muscle

Coxsackie B viruses have been causally linked to myocarditis in both children and adults, ${ }^{12}$ as well as to dilated cardiomyopathy. ${ }^{3}$ Although coxsackie viruses have a strong tropism for heart and skeletal muscle, ${ }^{4}$ successful viral isolation from myocardial tissue is very uncommon $^{2}$ and epidemiologic studies only rely on peripheral isolation or serology. ${ }^{5}$ Furthermore the ultrastructural identification of the virus in heart and skeletal muscle is anecdotal. ${ }^{78}$ Therefore, the need to prove the presence of the virus in affected hearts led to the development of molecular procedures ${ }^{9-13}$ on which viral RNA detection is presently based. While there is a general agreement on the association between coxsackie $B$ virus infection and myocarditis, the role of the virus in cardiomyopathy is still debated; molecular data do not provide certainty. An elegant meta-analysis by Baboonian and Treasure reported an overall odds ratio of $3.8 .{ }^{14}$ Recently, viral localisation and persistence in extracardiac sites has been reported in patients with dilated cardiomyopathy, ${ }^{15}$ thus opening new frontiers for investigating the role of the virus in the disease.

We report on two patients with acute myocarditis, in whom the virus was detected in both cardiac and skeletal muscle with both ultrastructural study and reverse transcription polymerase chain reaction (RT-PCR). These data document the occurrence of skeletal muscle infection in acute enteroviral myocarditis and support our prior observations ${ }^{15}$ that skeletal muscle may host the virus and constitute a chronic reservoir.

\section{Case 1}

A 39 year old man was admitted to our hospital in cardiogenic shock. He was in good health until five days before, when he had a febrile illness with productive cough and dyspnoea. After three days of antibiotic and antipyretic treatment, the fever was only partially controlled, but the dyspnoea progressively worsened, with severe orthopnoea during the night before hospitalisation. Next morning he was admitted to the cardiology division with a diagnosis of ventricular tachycardia, cardiogenic shock, and suspected myocarditis. Anamnesis and family history were negative.

The patient displayed signs of severe distress (confusion, orthopnoea, paleness, and profuse perspiration). His arterial blood pressure was $80 / 60 \mathrm{~mm} \mathrm{Hg}$, with radial pulse after cardioversion of 120 beats/min, and a body temperature of $38^{\circ} \mathrm{C}$. The neck veins were distended. The jugular venous pulse displayed a prominent presystolic wave. The lungs were hypoventilated at the bases. Distinct atrial and ventricular gallop sounds were audible. The liver was slightly tender and palpable $1 \mathrm{~cm}$ below the costal margin. Overall, the clinical picture was dominated by cardiogenic shock. After cardioversion, the ECG showed right bundle branch block and left axial deviation. On chest radiography the heart shadow was not enlarged. There was severe pulmonary congestion and bilateral pleural effusion. Laboratory data were: haemoglobin $149 \mathrm{~g} / 1(2.31 \mathrm{mmol} / \mathrm{l})$; haematocrit 0.359; white blood cell count $21.1 \times 10^{3}$; erythrocyte sedimentation rate $49 \mathrm{~mm}$ in the first hour; glucose $248 \mathrm{mg} / \mathrm{dl}$ (13.77 mmol/1); creatinine $\quad 2.35 \mathrm{mg} / \mathrm{dl}$ 


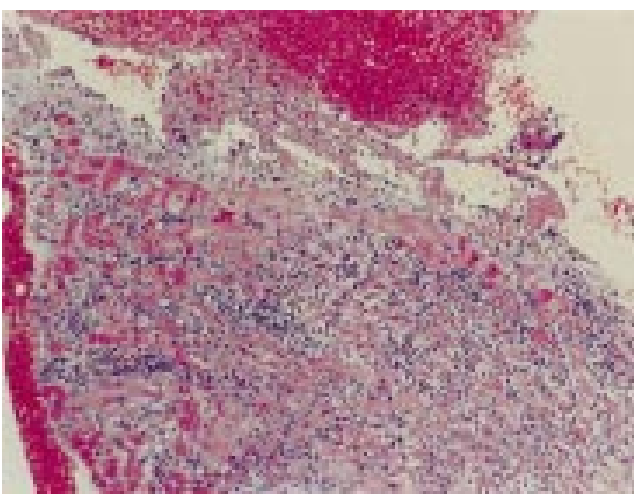

Figure 1 Low power view of the myocarditis diagnosed at necropsy in patient 1. Haematoxylin and eosin stain $\times 80$.

$(176 \mu \mathrm{mol} / \mathrm{l})$; uric acid $120 \mathrm{mg} / \mathrm{dl}(7.2 \mathrm{mmol} /$ 1); alkaline phosphatase $205 \mathrm{U} / 1$; total bilirubin $1.34 \mathrm{mg} / \mathrm{dl} \quad(22 \mu \mathrm{mol} / \mathrm{l})$; serum aspartate transaminase (SAST) $463 \mathrm{U} / 1$; lactate dehydrogenase $(\mathrm{LDH}) 2394 \mathrm{U} / 1$; creatine kinase (CK) $2429 \mathrm{U} / \mathrm{ml}$; isoenzyme of creatine kinase MB (CK-MB) $152 \mathrm{U} / \mathrm{l}$; sodium $130 \mathrm{mEq} / \mathrm{L}$; potassium $4.0 \mathrm{mEq} / \mathrm{L}$; chloride $94 \mathrm{mEq} / \mathrm{L}$. Two dimensional echocardiography showed pericardial effusion and a diffusely hypokinetic left ventricle that was not enlarged. On right catheterisation, pulmonary wedge pressure was $20 \mathrm{~mm} \mathrm{Hg}$ and cardiac index was $1.5 \mathrm{l} / \mathrm{min} / \mathrm{m}^{2}$.

MANAGEMENT

The patient was immediately treated with diuretics and infusions of dobutamine and dopamine, without definite clinical improvement; he was then placed on an aortic balloon pump. Over the next five hours the dyspnoea progressively increased and the patient's overall condition worsened; he had repeated episodes of high rate ventricular tachycardia, which were controlled with electrical cardioversions. Eight hours after admission he died from irreversible cardiogenic shock.

PATHOLOGIC FINDINGS

At necropsy there was moderate pericardial effusion $(500 \mathrm{ml})$. The heart weighed $450 \mathrm{~g}$ and was nearly normal in size. Left and right ventricular thicknesses were $1.2 \mathrm{~cm}$ and $0.2 \mathrm{~cm}$, respectively; multiple, non-contiguous pale areas with irregular borders were seen in the posterior, lateral, and anteroseptal walls of the left ventricle. No coronary narrowing was seen. Acute myocarditis was diagnosed on frozen sections, cut during necropsy. Both lungs were severely congested and oedematous; pleural effusion was bilaterally present. Multiple samples of different organs and tissues were processed for conventional histopathologic study and for electron microscopy. Further heart and muscle samples were frozen for molecular studies. ${ }^{11}{ }^{15}$ Conventional histologic study confirmed the diagnosis (fig 1). Ultrastructural study of heart and skeletal muscle samples identified virus-like particles and aggregates that were differently arranged in the heart and in skeletal muscle. In skeletal muscle the particles clustered in crystalline arrays, identical to those described in the skeletal muscle of dilated cardiomyopathy patients (fig $2 \mathrm{~A})^{15}$ and to those observed in the infected VERO cells (fig 2C). In heart samples they were identifiable as single particles or clustered together, but not crystallised into the typical arrays. Alternatively, they were regularly attached to the reticular membranes. These ultrastructural features were identical to those observed in coxsackie B3 infected VERO cells. RT-PCR and nested RT-PCR ${ }^{11}{ }^{15}$ on heart and skeletal muscle RNA gave positive amplifications for the 5 ' non-coding region of the viral genome (fig 3). Automated sequencing of the

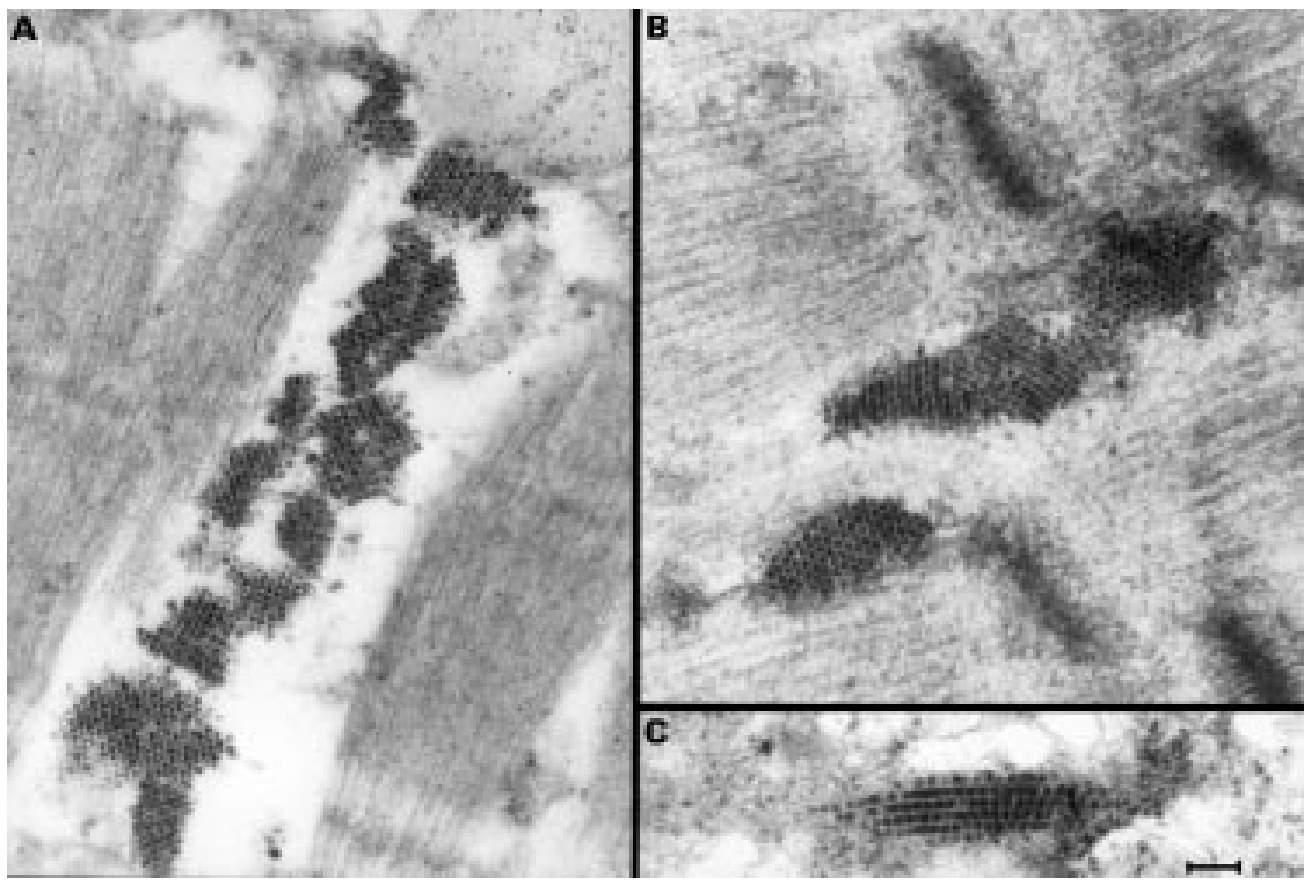

Figure 2 Electron micrographs showing viral crystalline arrays in the skeletal muscle of: (A) patient 1; (B) patient 2; and (C) coxsackie B3 infected VERO cells. Uranyl acetate and lead citrate (bar scale $0.25 \mu \mathrm{m}$ ). 


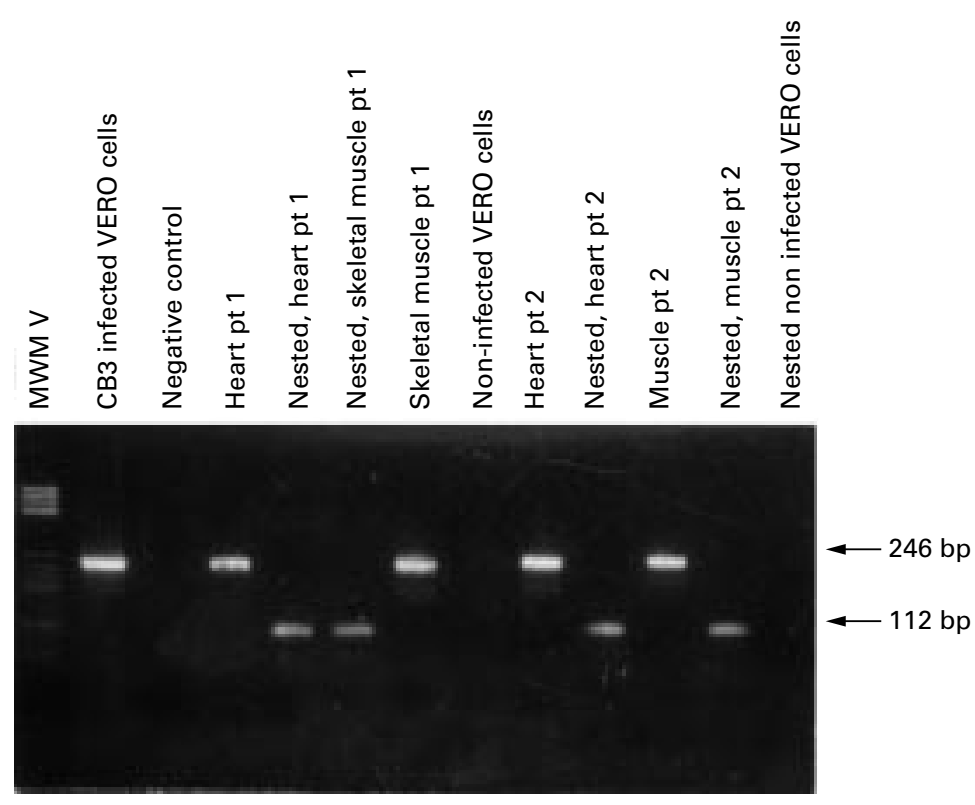

Figure 3 Reverse transcription PCR products from: coxsackie B3 (CB3) infected VERO cells (lane 1); negative control (lane 2); patient 1, heart and relative nested assay (lanes 3 and 4) and skeletal muscle (lanes 5 and 6, nested is in lane 5); non-infected VERO cells; PCR product external primers (lane 7); patient 2 heart and relative nested assay (lanes 8 and 9) and skeletal muscle (lanes 10 and 11); nested reaction from non-infected VERO cells (lane 12). MWM, molecular weight marker.

PCR products, sequence alignment, and comparison (basic local alignment search tool $(\text { BLAST })^{16}{ }^{17}$ ) proved the coxsackie $\mathrm{B}$ virus origin of amplified products, and excluded contamination.

\section{Case 2}

A 48 year old woman was referred to our centre from another hospital for cardiogenic shock dating back one day. One month before she had an acute episode of enteritis, which resolved in one day. Two weeks later she had a febrile episode $\left(38^{\circ} \mathrm{C}\right.$ up to $\left.39.5^{\circ} \mathrm{C}\right)$, which resolved with antibiotics and antipyretic treatment. Five days before admission, the patient complained of dyspnoea and asthenia which progressed to cardiogenic shock, associated with a new episode of enteritis, one day before. Dopamine and dobutamine infusions did not substantially improve the clinical course. The admission diagnosis was cardiogenic shock and suspected acute myocarditis. Anamnesis and family history were negative.

The patient was in severe distress, with orthopnoea, paleness, and profuse perspiration. Her arterial blood pressure was 80/ $60 \mathrm{~mm} \mathrm{Hg}$, a radial pulse of 148 beats $/ \mathrm{min}$ in sinus rhythm, and a body temperature of $37.5^{\circ} \mathrm{C}$. Her neck veins were distended. Pulmonary rales were heard at the lung bases. The heart sounds were reduced in intensity and a distinct ventricular gallop was audible. The liver was palpable about $4 \mathrm{~cm}$ below the costal margin. On ECG there was right bundle branch block and low voltage QRS complexes. On chest radiography the heart shadow was not enlarged. There were severe pulmonary congestion and pleural effusion. Two dimensional echocardiography showed pericardial effusion and a diffusely hypokinetic left ventricle that was not enlarged; end diastolic left ventricular diameter was $55 \mathrm{~mm}$ and ejection fraction was $20 \%$. Laboratory data included: haemoglobin $118 \mathrm{~g} / 1$ (1.83 mmol/1); haematocrit 0.345; white blood cell count $13.7 \times 10^{3}$; erythrocyte sedimentation rate $60 \mathrm{~mm}$ in the first hour; glucose $185 \mathrm{mg} / \mathrm{dl}(10.27 \mathrm{mmol} / \mathrm{l})$; creatinine $1.53 \mathrm{mg} / \mathrm{dl}(115 \mu \mathrm{mol} / \mathrm{l})$; uric acid $11.4 \mathrm{mg} / \mathrm{dl}$ (0.68 mmol/1); alkaline phosphatase $99 \mathrm{U} / 1$; total bilirubin $0.65 \mathrm{mg} / \mathrm{dl}(10.8 \mu \mathrm{mol} / \mathrm{l})$; SAST $142 \mathrm{U} / 1$; serum glutamic pyruvic transaminase (SGPT) $213 \mathrm{U} / 1 ; \gamma$ glutamyltransferase $27 \mathrm{U} / 1$; LDH 1636 U/1; CK 558 U/1; CK-MB 59 U/ 1; sodium $130 \mathrm{mEq} / 1$; potassium $3.6 \mathrm{mEq} / 1$; chloride $94 \mathrm{mEq} / 1$.

\section{MANAGEMENT}

An intra-aortic balloon pump was placed immediately after admission. The treatment with diuretics and infusions of dobutamine and dopamine was continued; furthermore, based on the clinical diagnosis of myocarditis, the patient was given steroids and azathioprine. An endomyocardial biopsy was performed immediately after admission and the diagnosis of acute myocarditis was confirmed upon frozen section examination. The RTPCR assay on myocardial tissue for enteroviral RNA search gave positive results. Immunosuppressive treatment was suspended and immunoglobulins were administered. Cardiac function did not improve and renal and hepatic failure progressively worsened. It was decided to implant a left ventricle assist device (LVAD). A muscular biopsy was performed during the LVAD procedure. The patient was stable for 54 days, with improved kidney and liver function, awaiting LVAD weaning or heart transplantation, but she died from a cerebral haemorrhage two months after LVAD implantation.

\section{PATHOLOGIC FINDINGS}

Light microscopy study showed necrotising myocarditis. The skeletal muscle sample obtained at LVAD implantation showed mild inflammatory myositis. Samples of both heart and muscle were processed for electron microscopy and frozen for molecular studies. Ultrastructural study identified virus-like particles and aggregates in heart and skeletal muscle (fig 2B). The viral particles were arranged differently in cardiac myocytes and in skeletal muscle cells as described in patient 1 , and were identical to those observed in the infected VERO cells as well as to those described in the skeletal muscle of dilated cardiomyopathy patients. ${ }^{15}$

RT-PCR on RNA from heart and skeletal muscle gave positive amplifications for the 5' non-coding region of the viral genome. Nested assays confirmed the results (fig 3). Sequencing of nested RT-PCR products, sequence alignments, and comparison (BLAST ${ }^{16}{ }^{17}$ ) proved the coxsackie B virus origin of amplified products and excluded contamination.

\section{Discussion}

In these two cases of enteroviral myocarditis, the infection was concomitantly documented 
in the skeletal muscle and in the heart of the affected patients. Furthermore, the extensive ultrastructural study done on multiple myocardial and skeletal muscle samples as well as on coxsackie B3 infected VERO cells allowed us to characterise the pattern of viral infection in skeletal and cardiac muscle. The high amount of virus in the skeletal muscle was clinically parallelled by a relative paucity of peripheral symptoms; only the first patient complained of a mild myalgia during his flu syndrome. The acute clinical picture was dominated by the myocardial involvement and both patients died from myocardial disease. In contrast, skeletal muscle infection can be symptomless. These observations raise several interesting issues from both the clinical and pathophysiological point of view.

The diagnosis of the viral aetiology of a biopsy proven myocarditis can be troublesome and relies on molecular identification of viral RNA. It is likely that viral particles may escape morphologic detection by electron microscopy because in the myocardium they do not arrange in crystalline structures. Virus-like particles or aggregates may only be morphologically detectable when they are crystallised or are so numerous as to be recognised, as in the cases reported here. In our cases the morphologic identification of the viruses was facilitated by the finding of typical crystallised arrays in the skeletal muscle and by our prior observations in dilated cardiomyopathy patients that enteroviruses can selectively localise in the skeletal muscle. ${ }^{15}$ In a recent study by Ukimura and colleagues on murine coxsackie virus B3 myocarditis, ultrastructural in situ hybridisation was able to detect viral RNA in the myocardium, but no individual viral particles were seen on days 5, 8, and 14 after inoculation of the virus. ${ }^{18}$ The reason why the same virus in similar cells types (striated heart and skeletal muscle) does not arrange in identical patterns is unclear; the restless myocardial cells could limit or prevent the aggregation of viral particles into fixed crystalline structures.

Why the virus injures the heart, inducing a dramatic inflammatory response in the myocardium, while it is accommodated innocuously in the skeletal muscle, is also a very important but, unfortunately, as yet unanswered question.

On the basis of published ${ }^{15}$ and unpublished observations we hypothesise that in non-fatal myocarditis evolving as dilated cardiomyopathy, the skeletal muscle may serve as permanent/persistent reservoir of the virus with some, still undetermined, provocative role. In a prior study we reported the surprising finding of both enteroviral particles and viral RNA in the skeletal muscle of patients with non-familial dilated cardiomyopathy. In more than one third of the investigated cases, nested RT-PCR identified enteroviral RNA in the skeletal muscle, and electron microscopy showed viral particles in four of the 12 PCR positive muscle samples. No virus was seen in the corresponding hearts and only three of the
12 cases with positive muscle had a positive PCR assay in the heart. Based on this observation we hypothesise that skeletal muscle rather than heart may be the reservoir of the virus. ${ }^{15}$ Spleen is a possible alternative site of virus persistence and latency. ${ }^{19}$

Why and how a chronic myocardial process takes place is unclear. Periodical reactivations of the viral infection might occur, based on the immunologic background. ${ }^{20-22}$ Alternatively, an autoimmune mechanism could be involved, as most of the autoantibodies detected in dilated cardiomyopathy patients are against proteins/epitopes shared by both cardiac myocytes and skeletal muscle cells. ${ }^{23}$ Accordingly, myocytolosis in either cell types could expose antigens that are normally segregated, and could trigger autoantibody generation. ${ }^{24}{ }^{25} \mathrm{In}$ an integrated hypothesis, both chronic infection with periodic reactivation and autoantibody generation could occur. Furthermore, given that cytolytic cross reactive antibodies against both cardiac sarcolemma and viral proteins have been identified in coxsackie B3 and B4 myocarditis, ${ }^{26}$ an antigen mimicry process could be advocated. Whatever the mechanism involved in the possible pathogenic role of enterovirus related cardiomyopathy, the presence of the virus in skeletal muscle is an important finding. Its easy detection might be of help in the diagnosis of both enteroviral acute myocarditis and chronic heart disease.

This work was supported by grants from Ricerche Finalizzate IRCCS Policlinico San Matteo- Health Ministry.

1 Burch GE, Sun SC, Chu K, et al. Interstitial and coxsackie virus $\mathrm{B}$ myocarditis in infants and children. $f A M A$ 1968;203:1-8.

2 Longson M, Cole FM, Davies D. Isolation of a coxsackie virus $\mathrm{B}$, type 5 , from the heart of a fatal case of myocarditis in an adult. F Clin Pathol 1969;22:654-8.

3 Quigley PJ, Richardson PJ, Meany DT, et al. Long term follow-up in biopsy proven myocarditis: progression to follow-up in biopsy proven myocarditis: prog
dilated cardiomyopathy. Circulation $1986 ; 74: 142$.

4 Crowell RL, Landau BJ, Lee Hsu KH, et al. Perspective on Crowell RL, Landau BJ, Lee Hsu KH, et al. Perspective on
cellular receptors as determinants of viral tropism. In: cellular receptors as determinants of viral tropism. In: update. New York: Plenum Press, 1988:35-40.

update. New York: Plenum Press, 1988:35-40.
5 El-Hagrassy MMO, Banatvala JE, Coltart DJ. Coxsackie-BEl-Hagrassy MMO, Banatvala JE, Coltart DJ. Coxsackie-B-
virus specific IgM responses in a patient with cardiac and other diseases. Lancet 1980;ii: 1160-2.

6 McCartney RA, Banatvala JE, Bell EJ. Routine use of mu-antibody-capture ELISA for serological diagnosis of coxsackie B virus infection. F Med Virol 1986;19: 205-12.

7 Neustein HB, Laurie PR. Endomyocardial biopsy in children: applications. In: Fenoglio JJ, ed. Endomyocardial biopsy: techniques and applications. Boca Raton, Florida: CRC Press, 1982:125-54.

8 Gyorkey F, Cabral GA, Gyorkey PK, et al. Coxsackievirus aggregates in muscle cells of a polymyositis patient. Intervirology 1978;10:69-77.

9 Bowles N, Richardson P, Olsen E, et al. Detection of coxsackie-B-virus-specific RNA sequences in myocardial biopsy samples from patients with dilated cardiomyopathy biopsy samples from patients with dilated

10 Easton AJ, Eglin RP. The detection of coxsackievirus RNA in cardiac tissue by in situ hybridization. $\mathcal{F}$ Gen Virol 1988; 69:285-91.

11 Grasso M, Arbustini E, Silini E, et al. Search for coxsackievirus B3 RNA in idiopathic dilated cardiomyopathy using gene amplification by polymerase chain reaction. $A m \mathcal{F}$ Cardiol 1992;69:658-64

12 Jin O, Sole MJ, Butany JW, et al. Detection of enterovirus RNA in myocardial biopsies from patients with myocarditis and cardiomyopathy using gene amplification by polymerase chain reaction. Circulation 1990;82:8-16.

13 Tracy S, Wiegand V, McManus B, et al. Molecular approaches to enteroviral diagnosis in idiopathic cardiomyopathy and myocarditis. f Am Coll Cardiol 1990;15:168894.

14 Baboonian C, Treasure T. Meta-analysis of the association of enteroviruses with human heart disease. Heart 1997;78: 539-43. 
15 Arbustini E, Grasso M, Porcu E, et al. Enteroviral RNA and virus-like particles in the skeletal muscle of patients with idiopathic dilated cardiomyopathy. Am $\mathcal{f}$ Cardiol 1997;80: 1188-93.

16 Altschul SF, Gish W, Miller,W, et al. Basic local alignment search tool. f Mol Biol 1990;215:403-10.

17 Altschul SF, Madden TL, Schäffer AA, et al. Gapped BLAST and PSI-BLAST: a new generation of protein database search programs. Nucleic Acids Res 1997;25:3389402.

18 Ukimura A, Deguchi H, Kitaura Y, et al. Intracellular viral localization in murine coxsackievirus-B3 myocarditis: ultrastructural study by electron microscopic in situ hybridization. Am 7 Pathol 1997;150:2061-74.

19 Klingel K, McManus BM, Kandolf R. Enterovirus-infected immune cells of spleen and lymph nodes in the murine model of chronic myocarditis: a role in pathogenesis. Eur model of chronic myocarditis: a

20 Gillespie JS, Cavanagh HM, Behan WM, et al. Increased transcription of interleukin- 6 in the brains of mice with chronic enterovirus infection. f Gen Virol 1993;74:741-3.
21 Schulteiss HP, Pauschinger M, Kuhl U. Pathogenesis of inflammatory cardiomyopathies. Med Klin 1998;93:229-35. Kandolf R. The molecular pathogenesis of enterovirus myocarditis: virus persistence and chronic inflammation. Internist 1995;36:430-8.

23 Latif N, Baker CS, Dunn MJ, et al. Frequency and specificity of antiheart antibodies in patients with dilated cardiomyopathy detected using SDS-PAGE western blotting. F Am Coll Cardiol 1993;22:1378-84.

24 Seko Y, Shinkai Y, Kawasaki A, et al. Evidence of perforin-mediated cardiac myocyte injury in acute murine myocarditis caused by coxsackie virus B3. F Pathol 1993;170:53-8.

25 Herzum M, Ruppert V, Kuytz B, et al. Coxsackievirus B3 infection leads to cell death of cardiac myocytes. $7 \mathrm{Mol} \mathrm{Cell}$ Cardiol 1994;26:907-13.

26 Maisch B, Bauer E, Cirsi M, et al. Cytolytic cross-reactive antibodies directed against the cardiac membrane and viral proteins in coxsackievirus B3 and B4 myocarditis: characterization and pathogenetic relevance. Circulation 1993;87: IV49-65.

\section{Electronic Pages}

\section{eHEART: www.heartjnl.com}

The following electronic only articles are published in conjunction with this issue of Heart.

\section{Diagnosis of apical hypertrophic cardiomyopathy using magnetic resonance imaging}

T Ibrahim, M Schwaiger

Apical hypertrophic cardiomyopathy is an uncommon variant of non-obstructive hypertrophic cardiomyopathy with low prevalence outside East Asia. A case is reported of a nonAsian (European) 51 year old man with characteristic ECG and morphological changes of apical hypertrophic cardiomyopathy. Although the patient underwent catheterisation three years previously because of suggested coronary ischaemic heart disease, apical hypertrophic cardiomyopathy was not diagnosed. More recently, a regional wall motion abnormality was noticed at the apex on echocardiography. To rule out an ischaemic injury a stress perfusion scintigraphy was performed; no perfusion defect was present but an apical tracer enhancement was noted. Further evaluation by magnetic resonance imaging revealed the pathognomonic "ace of spades" configuration of the left ventricle with systolic obliteration of the apical region, which led to the diagnosis of apical hypertrophic cardiomyopathy.

(Heart 2000;83:e1) www.heartjnl.com/cgi/content/full/83/ $1 / \mathrm{e} 1$

A 72 year old woman with ALCAPA $C$ Fierens, $W$ Budts, $B$ Denef, $F$ van De Werf

ALCAPA syndrome (anomalous origin of the left coronary artery from the pulmonary artery), which causes the left coronary artery to grow with an anomalous origin from the pulmonary artery, is a rare disease which may result in myocardial infarction, congestive heart failure, and sometimes death during the early infantile period. A 72 year old woman with ALCAPA syndrome is presented. The asymptomatic patient presented with a cardiac murmur which was discovered during a routine check up for a gynaecological intervention. Coronary cineangiography established the diagnosis. Although surgical correction is the usual treatment for such cases, medical treatment was preferred for this patient because she was asymptomatic without clinical signs of heart failure.

(Heart 2000;83:e2) www.heartjnl.com/cgi/content/full/83/ $1 / \mathrm{e} 2$

\section{Mycotic aneurysm of the ascending aorta following CABG}

$M$ Prech, S Grajek, A Cieśliński, $M$ femielity

Mycotic aneurysm of the thoracic aorta is a rare and life threatening condition. Two patients are presented (both male, aged 66 and 59 years) in whom coronary artery bypass surgery was complicated by the development of a mycotic aneurysm. Fever preceded the radiological and echocardiographic signs of the aneurysm by at least several months in both cases. Blood cultures were negative for one patient and the source of Corynebacterium sp infection in the other was not determined for several months. Both patients died before surgery could correct the aneurysm.

(Heart 2000;83:e3) www.heartjnl.com/cgi/content/full/83/1/ e3 